УДК 621.396 .96

\title{
СТАТИСТИЧЕСКИЙ СИНТЕЗ И АНАЛИЗ ОПТИМАЛЬНОЙ СТРУКТУРЫ АДДИТИВНО-ШУМОВОГО СВЧ РАДИОМЕТРА
}

\author{
ВОЛОСЮК В. К., ПАВЛИКОВ В. В., ЖИЛА С. С.
}

\author{
Национальный аэрокосмический университет им. Н. Е. Жуковского \\ «Харьковский Авиационный Институт», \\ Украина, Харьков, 61070, ул. Чкалова, 17
}

\begin{abstract}
Аннотация. Синтезирован оптимальный алгоритм оценки яркостной температуры собственного радиотеплового излучения объектов разной физической природы в аддитивно-шумовом СВЧ радиометре. Разработана структурная схема, реализующая полученный алгоритм. Рассчитана предельная погрешность оценки искомого параметра. Исследована потенциальная флуктуационная чувствительность предложенного радиометра
\end{abstract}

Ключевые слова: оптимальный алгоритм; оценка яркостной температуры; предельная погрешность оценивания; потенциальная флуктуационная чувствительность

\section{ВВЕДЕНИЕ}

Аддитивно-шумовой СВЧ радиометр относится к измерительной технике и предназначен для измерения параметров собственного радиотеплового излучения объектов различной физической природы в системах радиолокации, дистанционного зондирования Земли, радиоастрономии, радиофизики и медицины.

Данный тип радиометров, в сравнении с известными одноканальными радиометрическими приемниками, обладает рядом достоинств $[1,2]$, среди которых инвариантность результатов измерений к нестабильности коэффициента усиления и высокая флуктуационная чувствительность.

Несмотря на преимущества этой схемы, ее структура разработана эвристическим путем. В ней недостаточно полно использованы ее потенциальные возможности. Усовершенствовать структуру аддитивно-шумового радиометра и повысить его эффективность возмож- но путем использования современных методов статистической оптимизации приема и обработки радиотепловых сигналов.

\section{ПОСТАНОВКА ОПТИМИЗАЦИОННОЙ ЗАДАЧИ}

На интервале времени наблюдения $[0, T]$ необходимо найти оптимальную оценку яркостной температуры $T_{s}^{\circ}(\vec{\lambda})$ источника излучения, наблюдаемого на фоне внутренних шумов додетекторной части радиометра при условии, что коэффициент усиления приемника нестабилен во времени, а во входном тракте к полезному сигналу периодически подмешивается шум эталонного источника.

\section{ИСХОДНЫЕ СООТНОШЕНИЯ}

Предполагается, что антенной регистрируется сигнал шумового радиотеплового излучения $s(t, \vec{\lambda})$ с неизвестными параметрами $\vec{\lambda}$, подлежащими оцениванию. Основным неиз- 